\title{
Simulation Quadrocopter's Catastrophic Landings
}

\author{
Blagitko B., Mochulsky Yu. \\ Department of Radiophysics and Computer Technologies \\ Ivan Franko Lviv's National University \\ Lviv, Ukraine \\ blagitko@gmail/com,mochulsky@ukr.net
}

\author{
Zajachuk I. \\ Centre of Mathematical Modeling \\ Pidstryhach Institute for Applied Problems of Mechanics \\ and Mathematics Ukrainian Academy of Science \\ Lviv, Ukraine,igorzaj@gmail.com
}

\begin{abstract}
By means of mathematical modeling, the main features of emergency landing of quadrocopter are determined. The results of simulate of the quadrocopter landings in cases of failure of one of four pairs of electric motor screw are given. The methods of safe landing of an unmanned quadrocopter in case of failure of one of four pairs of motor-screw are proposed. The basis of the proposed methods is to use a parachuting effect. Parachuting achieved by forced off the power of the motor, which is located at the opposite end of the same yoke as faulty motor As a result, the vertical speed of the quadrocopter at the time of landing significantly decreases in comparison with the speed of free fall.
\end{abstract}

Index Terms-quadrocopter, altimeter, 3-axis gyroscope, 3axis accelerometer, 3 -axis magnetometer, control.

\section{INTRODUCTION}

In most articles on the problems of the quadrocopter flight it is implicitly assumed that all four pairs of motor-screw and their control circuit are serviceable [1-4].. In practice, often there are those or other faults in the sequence of links: the control circuit - the motor-screw. When a malfunction suddenly appears during the quadrocopter flight, then an emergency situation occurs.

In this article through mathematical modeling the basic features of quadrocopter emergency landings are considered. The results of mathematical modelling of quadrocopter emergency landings after the appearance of failure of one of the four electric motor-screws are presented.

\section{SIMULATION OF THE QUADROCOPTER LANDINGS IN THE EVENT OF THE FAILURE OF ONE OF THE FOUR ELECTRIC MOTOR-SCREW}

The mathematical model of a quadrocopter in flight in the event that all four pairs of electric motor screw and the control scheme of them are regular are considered as two essentially different mathematical models. Actually mathematical model of the quadrocopter is the UAV the inputs of which are the values of the voltage supply of electric motors, and the outputs are the altitude and angles of the roll, pitch and yaw The mathematical model of the PD regulator is a system in which inputs a measured value from the sensors of height, the angles of the pith, the roll and the jaw, and the microcontroller implements the PD algorithm and outputs the voltage values of the electric motors.. The mathematical model of the quadrocopter in flight in the event that all four pairs of electric motor screw and the control scheme are useful, is described by the system of differential equations of the 16th order in the form of Cauchy [4].

In case of failure of one of the four pairs of electro-motorscrew quadrocopter, the following possible cases are possible: failure of the nasal steam motor-screw; failure of the tail-pair motor-screw: failure of the right pair of electric motor-screw; failure of the left pair motor-screw. The simulating of malfunctioning was performed by switching off the power of the faulty motor.

In order to solve the differential equations of the mathematical model of the quadrocopter, the implicit RungeKutta method TR-BDF2 was used (in the first stage of the equation integrate by the trapezium formula method, and in the second stage of the second order (differentiation formula back is used).

\section{RESULTS OF SIMULATION OF LANDING PROCESS OF} QUADROCOPTER IN FAILURE OF ANY PAIR OF MOTOR-SCREW

The landing of the quadrocopter occurs after it has been suspended at a height of $50 \mathrm{~m}$ above the point with coordinates $\mathrm{X}=0, \mathrm{Y}=0$. The quadrocopter "nose" leads in the direction plus by axis $\mathrm{X}$. In this case, the initial values of the angles of the pitch and the roll are zero, and the angle of yaw is $90^{\circ}$. Simulating the failure of a specific pair of electric motor screw is carried out by assigning the supply voltage of the corresponding motor to a value of $0.0 \mathrm{~V}$ for all moments of time $t=>$ ta, where ta is the moment of failure of a specific pair of the electric motor-screw of the quadrocopter. Finally, complete content and organizational editing before formatting. Please take note of the following items when proofreading spelling and grammar:

In all articles [1-4] of the simulations the quadrocopter motions are considered as movements of the material point of a mass $\mathrm{m}$. But the quadrocopter has a complex spatial structure with certain dimensions. In order to see not only the movement of the center of the masses of the quadrocopter, but also the idea of its rotation during an emergency landing, the movements of the two points of the quadrocopter, the center of mass and the nasal engine, were simulated.. On Fig. 1 and on Fig. 4 the dashed line shows the trajectory of the center of the masses of the quadrocopter, and the squares of the trajectory of the movement of the nasal engine. 
The results of mathematical modeling of the process of landing a quadrocopter in the event of a failure of one of the four pairs of the electric motor-screw of the quadrocopter are given in the form of a graph of trajectories of motion in Fig.1. Trajectory 1 reflects the process of landing a quadrocopter in the failure of the nose pair of electric motor screw, and trajectory 3 - in the event of failure of the tail pair, the motorscrew.

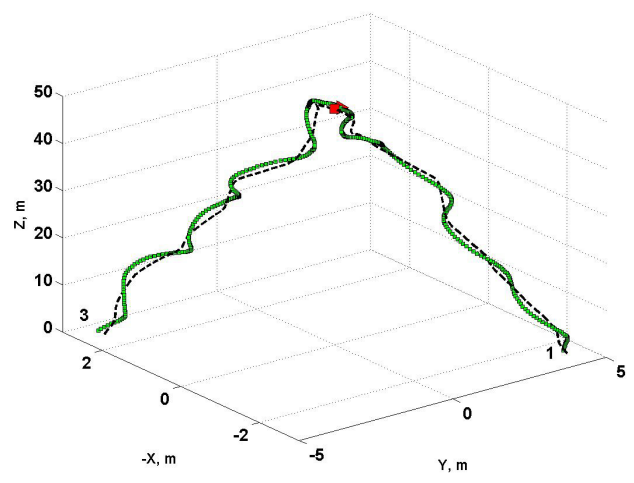

Fig. 1. Trajectories of the motion of the quadrocopter with the regulator: 1 -in case of failure of the nose pair motor-screw, 3 - in case of failure of the tail motor- screw.

Phase portraits of the angles of the Pitch, of the Jaw and of the Roll after having at the time ta $=1 \mathrm{~s}$ rejected the nasal engine, give to Fig. 2.

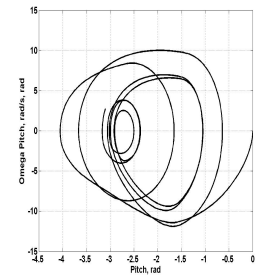

a) Pitch

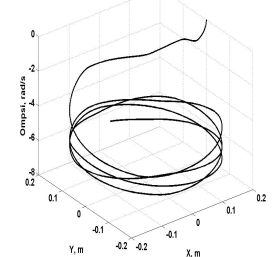

b) Jaw

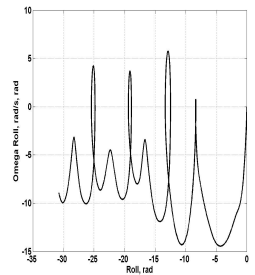

c) Roll
Fig. 2. Phase portraits of pitch, yaw and roll angles when the nose engine fails.

As can be seen from Fig.2, after the accidental disconnection of the nasal electric motor, the pitch angle begins to decrease (the quadrocopter "lowers" the nose). As shown in [3], the nasal and tail motors create the momentum of the forces that the quadrocopter rotates in relation to the vertical axis clockwise (if viewed from the bottom). The right and left motors rotate the quadrocopter counter-clockwise relative to this axis. Therefore, when the nasal engine fails, the quadrocopter starts to rotate counter-clockwise. The Pitch and Jaw create a gyroscopic moment of forces, which begins to rotate the quad oppressor relative to the longitudinal axis, that is, there is a roll. Having made a little more than one overspend relative to the transverse axis, the quadrocopter starts to rotate in the opposite direction, and in the future the Pitch ranges in the vicinity of $-150^{\circ}$. As for the longitudinal axis, the quadrocopter makes almost five turns in the negative direction and falls to the ground by the right engine.

Phase portraits of the angles of the Pitch, of the Jaw and of the Roll after having at the moment ta $=1 \mathrm{~s}$ rejected the tail engine, drawn on Fig. 3.

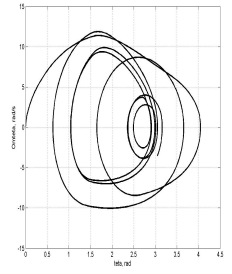

a) Pitch

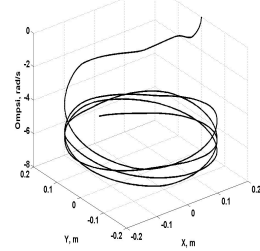

b) Jaw

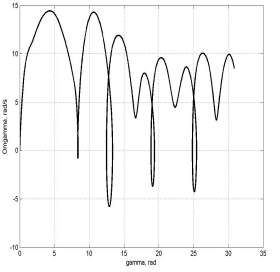

c) Roll
Fig. 3. Phase portraits of pitch, yaw and roll angles when the tail engine fails.

As can be seen from Fig. 3, after the emergency shutdown of the tail motor, the pitch angle begins to increase (quadrocopter "lowers" the tail). As indicated above, the nasal and tail motors rotate the quadrocopter relative to the vertical axis in the same direction. But the angular Pitch speed changed the direction of rotation to the opposite. Therefore, the gyroscopic moment of forces causes the quadrocopter's Roll in the opposite direction. By making more than one swing in a positive direction relative to the transverse axis, the quadrocopter starts to rotate in the opposite direction, and in the future the pitch fluctuates in the vicinity of $+150^{\circ}$. With regard to the longitudinal axis, the quadrocopter makes almost five turns in a positive direction and falls to the ground with the left engine.

The results of mathematical modeling of the process of landing of the quadrocopter in the event of failure of one of the other pairs of the electric motor screw quadrocopter are given in the form of a graph of trajectories of motion in Fig. 4. Trajectory 2 reflects the process of landing the quadrocopter with the failure of the right pair motor-screw, and trajectory 4 - in the case of failure of the left pair motor-screw.

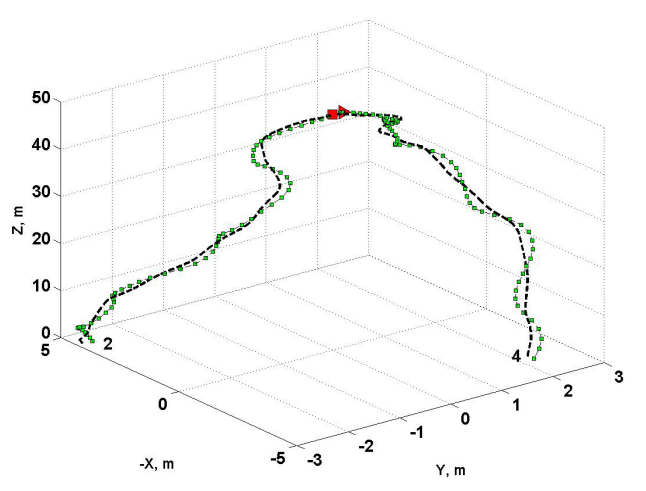

Fig. 4. Trajectories of the motion of the quadrocopter with the regulator: 2 - in case of failure of the right pair of electric motor- screw, 4 - in the failure of the left pair motor-screw 
Phase portraits of the angles of the Roll, of the Jaw and of the Pitch after having at the moment ta $=1 \mathrm{~s}$ rejected the right engine are shown in Fig. 5.

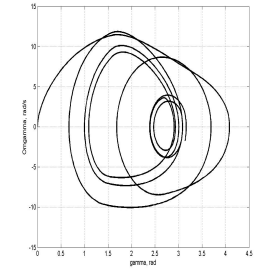

a) Roll

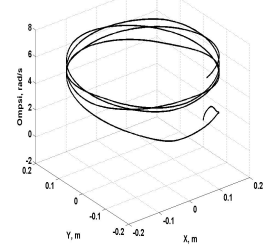

b) Jaw

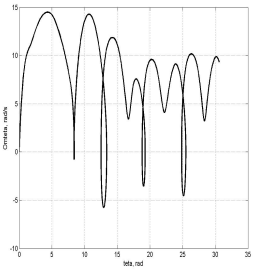

c) ) Pitch
Fig. 5. Phase portraits of roll, yaw and pitch angles when the right engine fails

As can be seen from Fig. 5, after the accidental trip of the right electric motor, the angle of the roll begins to increase (the quadrocopter "drops" to the right). The right and left engines create moment of forces, which rotates the quadrocopter relative to the vertical axis counterclockwise (if you look from below). Therefore, when the right engine fails, the quadrocopter starts to rotate clockwise. The Roll and Jaw create a gyroscopic moment of forces, which begins to rotate the quadrocopter relative to the transverse axis, that is, there is a pitch. Having made a little more than one overspend relative to the longitudinal axis, the quadrocopter begins to rotate in the opposite direction, and in the future the roll varies in the vicinity of $+150^{\circ}$. As for the transverse axis, the quadrocopter makes almost five turns in a positive direction and falls to the ground on the nasal motor.

Phase portraits for changing the angles of the roll and pitch after having turned off the left engine at the time ta $=1 \mathrm{~s}$, are shown in Fig. 6.

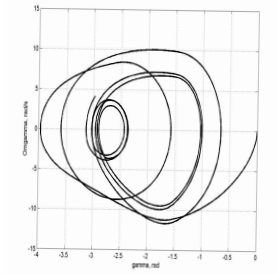

a) Roll

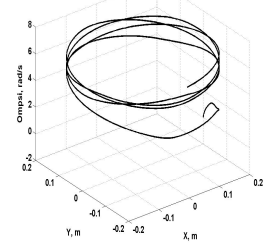

b) Jaw

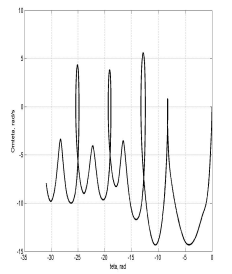

c) ) Pitch
Fig. 6. Phase portraits of roll, yaw and pitch angles when the left engine fails.

As can be seen from Fig. 6, after the emergency cut-off of the left electric motor, the angle of the roll begins to decrease (the quad-compressor "falls" to the left). At the same time, as a result of uncompensated moments of forces relative to the vertical axis, the quadrocopter starts to rotate clockwise. The gyroscopic moment of forces causes the quadrocopter Pitch. Having made a little more than one rotation relative to the longitudinal axis, the quadrocopter starts to rotate in the opposite direction, and in the future the roll varies in the vicinity of $-150^{\circ}$. As for the transverse axis, the quadrocopter makes almost five turns in the negative direction and falls to the ground on the tail engine.

It should be noted that the above-mentioned fall of the quadrocopter to the ground on one of the engines is valid only when a drop from a height of $50 \mathrm{~m}$ and zero initial angles of pitch and roll. Under other initial conditions, due to the rotation of the quadrocopter relative to all three axes, it is possible to fall to the ground in any position.

Emergency landing of a quadrocopter $r$ with failure of one of four pairs of electric motor screw has significant disadvantages, namely: unpredictable landing point, unpredicted speed at the time of landing, unpredicted duration of fall and its nature, unpredicted landing angle, and the like.

\section{Method of SAFE LANDing of QuAdROCOPTER WITH FAILURE OF ONE OF THE PAIRS OF ELECTRIC MOTOR-SCREW}

This article proposes a control method for the safe landing of a quadrocopter with a failure of one of the four pairs of electric motor screw. The proposed method is to forcibly shut off the electric motor, which in pairing with the already defective electric motor is located on the opposite end of the same console. This method uses the parachuting effect of the quadrocopter. Parachuting achieved by forced off the power of the motor, which is located at the opposite end of the same yoke as faulty motor As a result, the vertical speed of the quadrocopter at the time of landing significantly decreases in comparison with the speed of free fall.

For example, the simulation results of a safe landing of an emergency quadrocopter with a height of $50 \mathrm{~m}$ over a point with coordinates $\mathrm{X}=0, \mathrm{Y}=0$. Quadrocopter at the same time "hangs" motionless (the angles of the pitch and the roll are zero). The main parameters of the quadrocopter: mass - $468 \mathrm{~g}$, distance from the center of mass to the engine $-22.5 \mathrm{~cm}$, EMC battery $-11.1 \mathrm{~V}$.

Phase portraits of the angle of gravity for the proposed method of safe emergency landing of the quadrocopter are shown in Fig. 7 (in the case of the failure of the nosal engine and the instantaneous disconnection of the tail engine) and Fig. 8 (in the case of failure of the left engine and instant disengagement of the right motor).
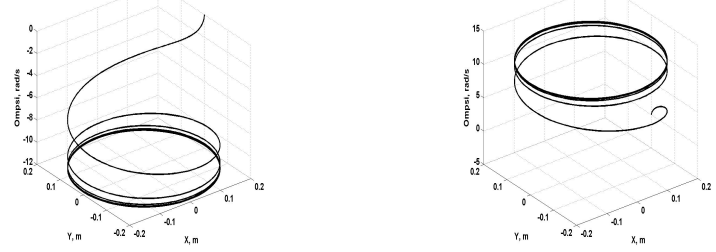

Fig. 7. Phase portrait of the angle of Jaw in the failure of the nose or tail engine.

Fig. 8. Phase portrait of the angle Jaw at the failure of the right or left engine..

Fig. 9 depicts a fragment of a safe emergency landing of a quadrocopter with a failure of the nasal engine and the instantaneous shutdown of the tail engine or with the cessation of the tail engine and the instantaneous disconnection of the nasal engine. 


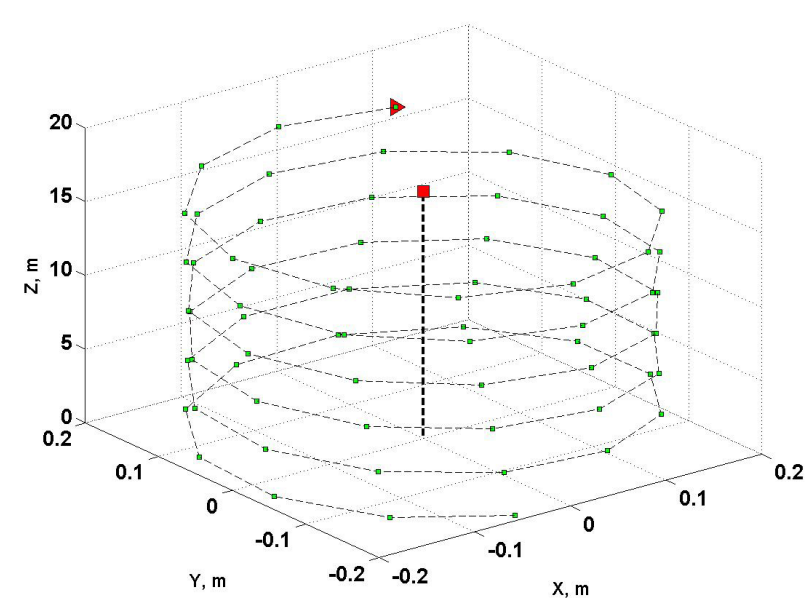

Fig. 9. Safe emergency landing of the quadrocopter at the failure of the nose or tail engine.

Fig.10 depicts a fragment of a safe emergency landing of a quadrocopter with a failure of the right engine and the instant disconnection of the left engine or the failure of the left engine and instant disabling of the right engine.

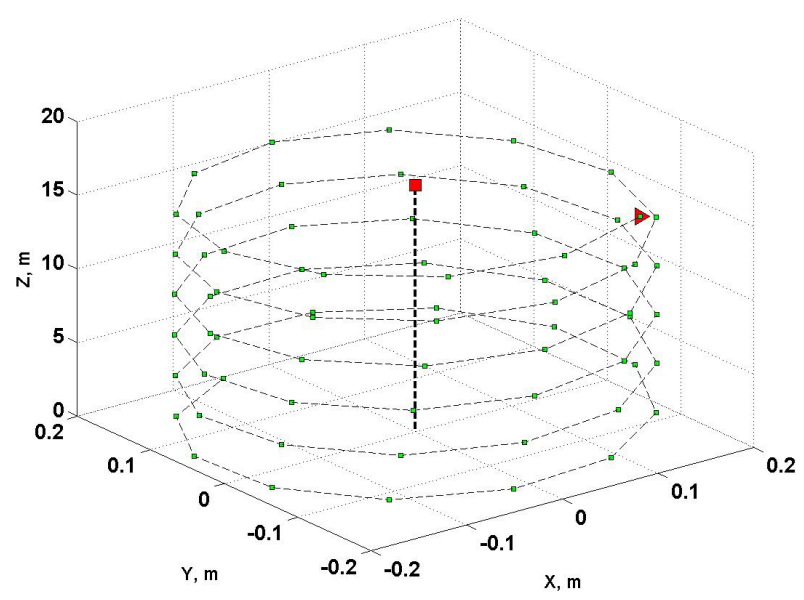

Fig. 10. Safe emergency landing of the quadrocopter with the failure of the left or right engine

When free fall all four engines are off, the quadrocopter reaches the ground in just 6 seconds. The vertical component of the landing speed at the same time is $16.5 \mathrm{~m} / \mathrm{s}$. In case of refusal of one engine and working three remaining during the time of reduction, there are moments of forces concerning the axes of pitch, roll and jaw. Therefore, the quadrocopter revolves against all three axes. Due to this, the rate of change does not change monotonously, but the vertical component of the landing speed decreases to $14 \mathrm{~m} / \mathrm{s}$ [8].
If simultaneously with the engine that is out of order, turn off the power of the electric motor, which is located at the opposite end of the same traverse as the defective electric motor, then the time of fall is $11.7 \mathrm{~s}$, and the vertical landing speed is $5.6 \mathrm{~m} / \mathrm{s}$. The horizontal components of the speed all the time will be zero, that is, the quadrocopter will fall vertically down. The roll and pitch during the fall are zero, that is, the quadrocopter will always land on the chassis. Due to the fact that in this case, not compensated moments of the forces of two opposite engines, the speed of rotation around the vertical axis at the time of landing will be $4.4 \mathrm{rad} / \mathrm{s}$. This speed will create a distance of $22.5 \mathrm{~cm}$ from the center of mass of the acceleration $4.4 \mathrm{~m} / \mathrm{s}^{2}$.

\section{CONCLUSION}

The results of the conducted research determine the effectiveness and practical significance of the use of the proposed methods of safe landing of the quadrocopter, which in the flight unexpectedly refused one of the four pairs of propeller. To reduce the vertical component of the landing speed when the failure of one of the engines it is expedient as soon as possible to disconnect the voltage from the opposite engine, which is located on the opposite end of the console. In this case, the horizontal components of the speed are practically zero.

\section{REFERENCES}

[1] Huang H. Aerodynamics and control of autonomous quadrotor helicopters in aggressive maneuvering / H. Huang. G. M. Hoffmann, S. L. Waslander, and C. J. Tomlin // IEEE International Conference on Robotics and Automation, May 2009, pp. 3277-3282.

[2] Wissiere D. Experimental autonomous flight of a small-scaled helicopter using accurate dynamics model and low-cost sensors / David Wissiere, Pierse-Jean Bristeau, Alain Pierse Martin, Nikolas Petit // Proceeding of the 17th Word Congress The International Federation of Automatic Control, Seoul Korea, July 6-11, 2008, pp. 14642-14650.

[3] Nartin P. The True Role of Accelerometer Feedback in Quadrotor Control / Philip Nartin, Erwan Salaun // IEEE International Conference on Robotics and Automation, Anchorage, May 2010, pp.1623-1629.

[4] Marcelo B. In-Flight Collision Avoidance Controller Based Only on OS4 Embedded Sensors/ B.Marcelo, R.C.B.Sampaio, S.Bounabdallah, V.de Perrot, R.Siegwart// Journal of the Brazilian Society of Mechanical Sciences and Engineering. vol.34 no.3 Rio de Janeiro July/Sept. 2012 March 2012. - Vol. XXXIV, No.3, July-September 2012- C. 294-107.

[5] Благітко Б. Моделювання процесу керування вертикальним злетом i приземленням безпілотного квадрокоптера /Б.Благітко, І.Заячук, Л.Кіт. Ю.Мочульський// Фізико-математичне моделювання та інформаційні технології.-2012-Вип.2-С.111-117

[6] Благітко Б. Математичне моделювання процесу стабілізації квадрокоптера у польоті / Б. Благітко, Ю. Мочульський // Електроніка та інформаційні технології.-2013. - Вип. 3. C. 96-107.

[7] Благітко Б. Математичне моделювання впливу особливостей сенсорів на процес польоту безпілотного квадрокоптера / Б. Благітко, І І. Заячук, Ю. Мочульський // Фізико-математичне моделювання та інформаційні технології.-2015.-Вип. 21 . C. $22-29$.

[8] Благітко Б. Аварійне приземлення квадрокоптера в безпілотному польоті / Б. Благітко, Ю. Мочульський // Електроніка та інформаційні технології. - 2017 - Вип. 8. -С. 137-142.

[9] Мочульський Ю. Matlab у фізичних дослідженнях: навч. - метод. посіб. — Львів: ВЦ ЛНУ ім. Івана Франка, 2004. — 121 с. 